\title{
FORMULAÇÃO E IMPLEMENTAÇÃO DE ESTRATÉGIAS DE PRODUÇÃO: UM ESTUDO DE CASO EM UMA EMPRESA MOVELEIRA
}

Diego Madalena ${ }^{1}$ Pierry Teza ${ }^{2}$

\section{Resumo}

Atualmente é possível observar as constantes mudanças pelas quais passa o ambiente, que é alterado em seus mais amplos e diversificados âmbitos, sejam eles culturais, políticos, econômicos ou sociais. No cenário empresarial, como um dos maiores afetados com as transformações ocasionadas, as organizações têm almejado cada vez mais resultados em função de redução de custos, ampliando seus esforços em qualidade, produtividade, competitividade e excelência. $\mathrm{O}$ presente trabalho investigou como são formuladas as estratégias de produção industrial em uma organização industrial do setor moveleiro. A abordagem de pesquisa adotada foi a qualitativa, sendo a estratégia de pesquisa o estudo de caso. Como resultados, verificou-se, entre outros, que: a) a organização não possui um processo de formulação de suas estratégias formalmente definido; b) a função produção na prática possui valorização da organização como diferencial competitivo; e c) a estratégia de produção não atinge os níveis operacionais de maneira eficiente. Ainda foram identificados os seguintes pontos de melhoria na formulação e implementação das estratégias de produção na organização: a) a comunicação entre as partes envolvidas no processo de formulação e implementação das estratégias de produção também pode ser otimizada pelo uso de rotinas formalizadas para tal; b) a organização deve evitar separar os processos de formulação e de implementação das estratégias, tendo em vista aproveitar contribuições dos diversos envolvidos, direta e indiretamente, no processo; e c) as categorias de decisão são tratadas e recebem os devidos planos de ações, porém não existe formalidade na categorização das decisões por parte da estratégia de produção.

Palavras-chave: Estratégias de Produção. Indústria Moveleira. Estudo de Caso.

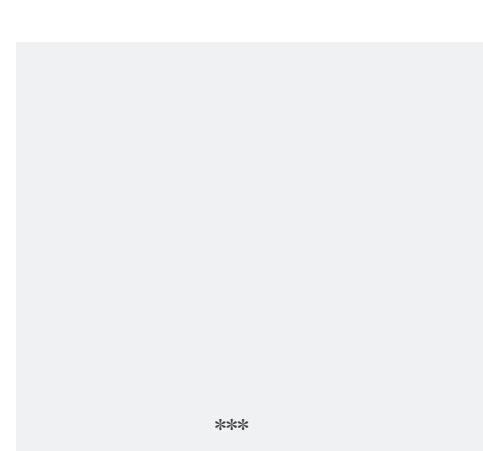

1 Especialista, e-mail: diegomdln@gmail. com

2 Mestre, e-mail: pierry. teza@gmail.com

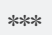




\section{INTRODUÇÃO}

$\mathrm{Na}$ atualidade,é possível observar as constantes mudanças pelas quais o ambiente é alterado em seus mais amplos e diversificados âmbitos, sejam eles culturais, políticos, econômicos ou sociais. Tais mudanças no ambiente competitivo alteraram sensivelmente as concepções básicas de como produzir bens. Uma diferenciação vem ocorrendo no setor industrial, em que a função produção deixou de ser apenas um componente produtivo e passou a ser um diferencial competitivo (CORREAA; GIANESI, 1994; SLACK et al., 2007).

A capacidade gerencial para controlaro processo de mudança dependerá dos conhecimentos sobre os fatores que favorecem ou provocam resistência às mudanças (MATTOS, 2002).

\section{NAS PRÁTICAS ADOTADAS}

NA GESTÃO INDUSTRIAL, SÃO

ENFATIZADAS A FORMULAÇÃO

E A IMPLANTAÇÃO DAS

ESTRATÉGIAS DE PRODUÇÃO,

PELAS QUAIS O GESTOR

DEVE DIRECIONAR AS AÇÕES

PRODUTIVAS, PARA ADEQUÁ-

LAS AOS OBJETIVOS DA

ORGANIZAÇÃO.

Para uma maximização dos resultados das organizações em função da competitividade empregada na função produção, são necessários cada vez mais o desenvolvimento e o aperfeiçoamento das técnicas e métodos empregados nas estratégias corporativas e de negócio, com o intuito de gerar as informações necessárias para formulação e implementação adequadas das estratégias de produção.

As estratégias de produção, ou estratégias funcionais, são aquelas em que as decisões levam em consideração as expectativas da organização, o dinamismo do consumidor e do mercado no qual a organização encontra-se inserida, as atividades de seus concorrentes e os recursos da empresa. A capacitação tecnológica, as habilidades das pessoas e a organização das funções são componentes indispensáveis nesta estratégia devido à necessidade de traduzir os objetivos do negócio, organizando os recursos para apoiá-1o. (SLACK et al., 2007).

Dado o contexto apresentado, este artigo relata os resultados de um estudo que objetivou investigar como são formuladas as estratégias de produção industrial em uma organização industrial do setor moveleiro. Nesse sentido, pretende-se fazer uma contribuição empírica ao tema estratégias de produção, baseando-se não apenas na literatura sobre o tema, mas também em trabalhos anteriores (por exemplo, PAIVA, 1999; CARIDADE, M. D.; TORKOMIAN, 2001; D'ANDRÉA, 2006).

$\mathrm{O}$ artigo segue apresentando, na seção 2, a fundamentação teórica utilizada no estudo. $\mathrm{Na}$ seção 3, são apresentados os procedimentos metodológicos utilizados, com vistas a alcançar o objetivo proposto. Na seção 4, são apresentados e discutidos os resultados obtidos. Finalmente, na seção 5, são explicitadas as considerações finais do trabalho. 


\section{FUNDAMENTAÇÃO TEÓRICA}

A presente seção tem como objetivo apresentar as principais bases teóricas utilizadas no estudo de caso apresentado. Para Mintzberg et al. (2000), a estratégia representa uma adaptação entre um ambiente dinâmico e um sistema de operações estável, em uma concepção de que a organização se ajusta continuamente ao ambiente em que está inserida. Segundo Porter (1986), o que determina o sucesso ou fracasso de uma organização é a concorrência. Nesse contexto, estratégia é a busca de uma posição favorável, estabelecendo lucratividade e sustentabilidade em função das forças que determinam a concorrência. Para Slack et al. (2002) e Paiva (2009), as estratégias são dividas de acordo com as influências hierárquicas que as definem: estratégia corporativa, a estratégia de negócios, estratégia funcional (também chamada por outros autores como operacional ou de produção).

A estratégia corporativa refere-se às decisões e organizações a um nível macro, ou seja, a definição de quais negócios adquirir, de como capitalizar os recursos financeiros necessários a tal aquisição e como gerenciar as relações entre os diferentes negócios. $\mathrm{O}$ ambiente externo, fatores econômicos, sociais e políticos, aliados aos aspectos culturais e aos valores dos dirigentes, são os principais fatores que influenciam as decisões deste nível estratégico (SLACK et al., 2002). De acordo com Barney e Hesterly (2011), as estratégias corporativas são aquelas em que, em geral, a organização atua em dois ou mais mercados simultaneamente.As principais estratégias corporativas são: integração vertical, diversificação; alianças estratégicas, fusões e aquisições, internacionalização (BARNEY;
HASTERLY, 2011), conforme disposição a seguir.

Sob a perspectiva de Barney e Hesterly (2011), a integração vertical é o nível de integração que uma empresa possui internamente em sua cadeia de valores. A integração pode ser para trás ou para frente: para trás, quando incorpora internamente estágios do início da cadeia de valores, e para frente, quando incorpora estágios mais ao fim da cadeia.Uma empresa implementa uma estratégia de diversificação corporativa quando opera em vários setores ou mercados simultaneamente. Segundo Barney e Hesterly (2011) ainda, uma aliança estratégica existe sempre que duas ou mais organizações independentes cooperam no desenvolvimento, na produção ou na venda de produtos ou serviços. Já os termos fusões e aquisições são geralmente utilizados de maneira intercambiável, embora não sejam sinônimos. Uma empresa faz uma aquisição quando compra uma segunda empresa. A fusão é considerada a estratégia pela qual duas empresas concordam em interagir suas operações de forma relativamente igual (HARRISON, 2005). Sob o aspecto internacionalização, Barney e Hesterly (2011) definem que a operação de empresas em diversos países simultaneamenteé resultado da implementação de estratégias de internacionalização.

A estratégia de negócios é estabelecida a cada unidade de negócio. Assim, consiste em orientar o negócio em um ambiente composto por mercados, consumidores e concorrentes, ou seja, a partir dela são definidas a missão, as metas, as formas de estabelecimento da competitividade no mercado e a maneira como serão 
coordenadas as atividades funcionais (SLACK et al., 2002). Segundo Barney e Hesterly (2011), uma empresa opta por adotar uma estratégia de negócio de liderança em custo, quando foca em ganhar vantagem competitiva por meio da redução de custos a níveis inferiores do que seus concorrentes. De maneira oposta, a estratégia de diferenciação de produto, que, segundo os autores, é uma estratégia de negócio em que as empresas buscam ganhar vantagem competitiva aumentando o valor percebido de seus produtos em relação aos valores de outras empresas.

Finalmente, as estratégias de produção, ou estratégias funcionais, são aquelas em que as decisões levam em consideração as expectativas da organização, e seu objetivo é traduzir os propósitos do negócio, organizando os recursos para apoiá-lo.(SLACKetal.,2002).Assim,nos três níveis hierárquicos, as estratégias de negócios geram o ambiente em que as estratégias funcionais operam e a estratégia corporativa gera o ambiente no qual a estratégia de negócios se aloca (SLACK et al., 2002). A estratégia corporativa visualiza a organização como um sistema de partes e áreas funcionais interconectadas, cada uma funcionando exatamente conforme o esperado, para alcançar os objetivos prospectados. (KRAJEWSKI, 2009).

\subsection{Estratégias de produção}

Para Corrêa e Gianesi (1994), o principal objetivo da estratégia de produção é o aumento da competitividade da organização por meio da padronização coerente de decisões e da organização dos recursos produtivos, para que a otimização destes recursos potencialize a competitividade no mercado de atuação da organização.
Skinner (1969) é um pouco mais abrangente ao considerar a estratégia como um composto de planos e políticas pelas quais a empresa pode almejar vantagens competitivas sobre seus competidores, o que inclui planos e políticas que se aplicam à produção e à venda de produtos a nichos específicos de consumidores.

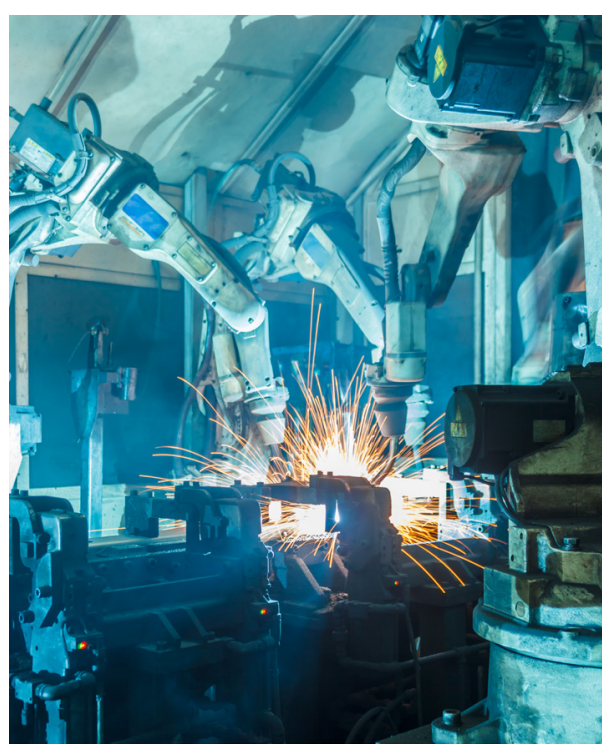

Após as considerações anteriores, verifica-se o enfoque dado à função produção, deixando de ser apenas um setor reativo às ações comerciais e de executora das ações estratégicas, passando a influenciar diretamente as definições estratégicas coorporativas. Dessa forma, procura-se tornar perceptível a conexão entre a estratégia coorporativa e a função produção das organizações.

Segundo Platts (2002),

ESTRATÉGIA DE PRODUÇÃO É

DEfINIDA COMO UM PADRÃO

DE DECISÕES QUE ENVOLVE

DUAS LINHAS PARALELAS DE

ASPECTOS: AS ESTRUTURAIS E AS

DE INFRAESTRUTURAS. 
Esses aspectos determinam a capacidade do sistema produtivo, bem como especificam como o sistema deverá operar o conjunto de objetivos produtivos a fim de consistirem com os objetivos competitivos da organização.

\subsection{Conteúdo das estratégias de produção}

Os principais componentes que definem o conteúdo de uma estratégia de produção são os critérios competitivos diretamente ligados à estratégia competitiva (ou de negócios) da empresa e às categorias de decisão a longo prazo, que influenciam diretamente as tomadas de decisão na função produção das organizações. Para Paiva (2009), como sistemática do processo de implantação da estratégia de produção, a organização deve definir os seus critérios competitivos, alinhando-os às suas estratégias de negócio. A função produção deverá utilizar tais critérios na adequação da estratégia de produção em função das categorias de decisões geradas sob cada critério. Dessa forma, ações serão tomadas mediante a análise de tais categorias, para dar suporte às necessidades geradas pelas estratégias de negócio e corporativa, conforme pode ser observado na Figura 1.

Figura 1: Conteúdo das estratégias de produção e a relação com as demais estratégias

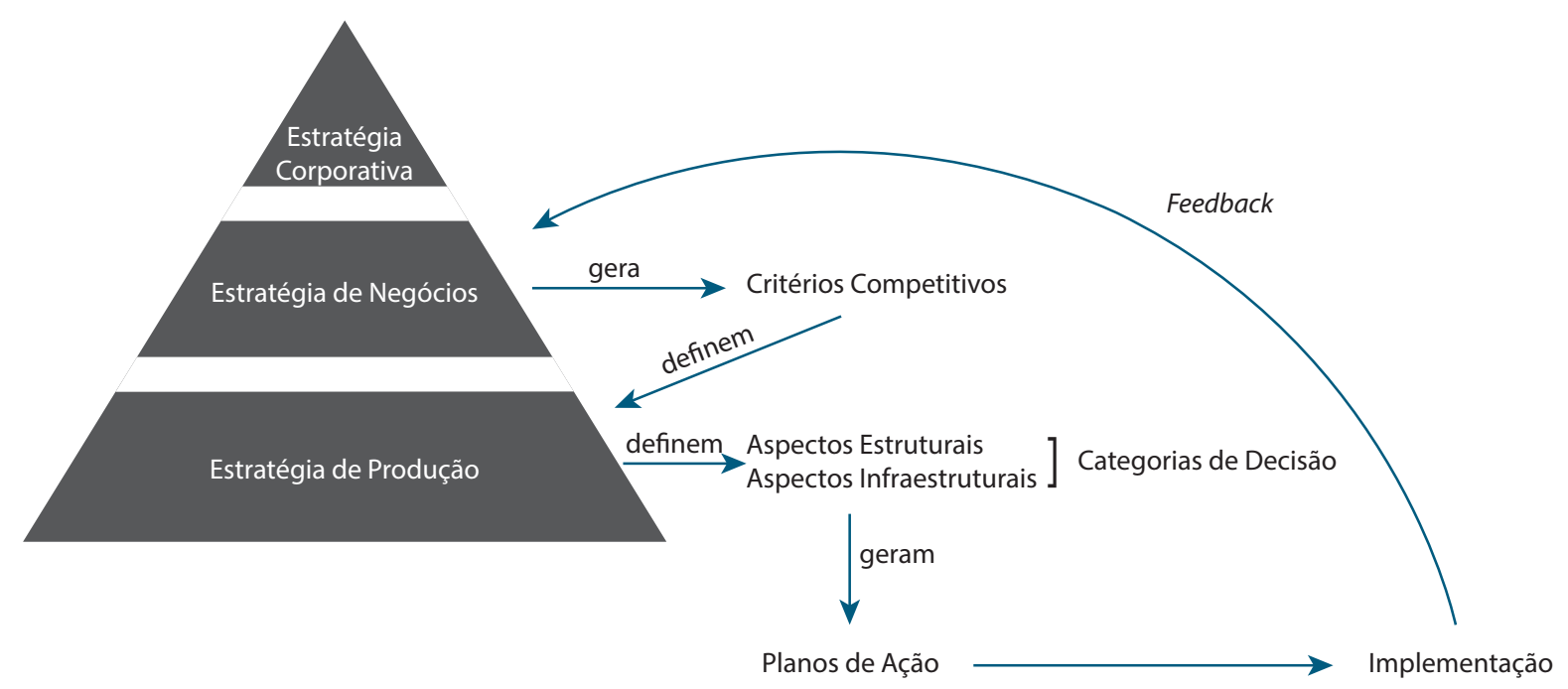

Fonte: Dos autores (2013)

O processo de integração das estratégias da organização, mostrado na Figura 2, está interligado. Dessa forma, uma ação leva a outra na organização como um todo. A aplicação da estratégia de produção nas empresas inicia-se pela definição de seus critérios competitivos, relacionados às estratégias corporativas e de negócio, em função do mercado em que se encontra inserida a organização. As estratégias de negócio, por sua vez, dão origem aos critérios competitivos, que formam um conjunto de prioridades que a organização deve valorizar para competir de forma igualitária no mercado onde se encontra inserida. Ou seja, em função das competências internas da empresa, do tipo de mercado, do mercado de atuação, do nível da concorrência e do tipo de produto que ela produz, a empresa deverá priorizar alguns critérios competitivos, maximizando a utilização de seus recursos, capacidades e oportunidades para se tornar competitiva. 
Dessa forma, observa-se que, conforme os recursos humanos, físicos e tecnológicos, das necessidades dos seus clientes e do desempenho dos concorrentes, os critérios competitivos são definidos de acordo com a melhor adequação à realidade da organização, para proporcionar a melhor estruturação possível da função produção, para que ela suporte, de forma satisfatória, tais critérios competitivos. Assim, a diferenciação das estratégias de produção aplicadas em diferentes empresas se deve ao peso de cada critério competitivo e à maneira como cada um é buscado efetivamente no dia a dia do setor de produção (SANTOS; PIRES, 1998). Esses elementos deverão gerar os planos de ação necessários para a implementação da estratégia, que finalmente podem proporcionar uma retroalimentação à estratégia de negócio com relação aos resultados em função dos critérios definidos.

Os critérios competitivos são divididos por Slack et al. (2007) em qualidade, rapidez/velocidade, confiabilidade, flexibilidade e custos, que, por sua vez, deverão gerar as categorias de decisões, representadas pelas ações que a função produção deverá realizar para que tais critérios competitivos sejam gerados. As categorias de decisões são divididas em dois grupos, as estruturais e infraestruturais. As categorias de decisão que compõem o grupo de decisões estruturais são classificadas em: capacidade de produção, instalações de produção, tecnologia de produção e integração vertical e relação com fornecedores. As categorias de decisão que compõem o grupo de decisões infraestruturais, segundo Slack et al. (2007), são classificadas em: planejamento, controle e organização da produção, força de trabalho e gerência de qualidade.

\subsubsection{Critérios competitivos}

Os principais elementos que definem o conteúdo de uma estratégia de produção são os critérios competitivos relacionados à estratégia competitiva da empresa e às categorias de decisão de longo prazo, que influenciam a tomada de decisão na função produção das empresas (SLACK et al., 2007). Swamidass e Newell (1987) consideram o conteúdo da estratégia da produção em quatro critérios competitivos: custo, qualidade, flexibilidade e confiabilidade. Já Muscate Fleury (1993) consideram as seguintes dimensões competitivas: custo, qualidade, tempo, flexibilidade e inovação. Conforme Salles (1998, p.68), a dimensão inovação é argumentada pela possibilidade de a organização ir além da flexibilidade, “[...] por não se tratar apenas de responder, ainda que de maneira rápida, à demanda estabelecida pelo mercado; inclusive criando novos mercados para produtos únicos e inovadores."

Slack et al. (2007), de maneira mais abrangente, retoma essa temática considerando que, quando se pretende compreender a contribuição do aspecto estratégia em qualquer atividade, é importante entender um cenário no qual se identifiquem os benefícios internos e externos em que as "atividades" se derivam da obtenção de cada um dos cinco objetivos de desempenho da empresa, caracterizados nas seguintes dimensões competitivas: custo, confiabilidade, flexibilidade, qualidade, rapidez. Com a mesma abrangência, Paiva (2009) considera que existem cinco critérios competitivos que se relacionam à estratégia de negócios, sendo eles os custos, a qualidade, o desempenho das entregas, a flexibilidade e a inovatividade. $\mathrm{O}$ Quadro 1 apresenta as definições dos critérios competitivos utilizados no estudo. 


\begin{tabular}{|c|l|}
\hline Critério Competitivo & \multicolumn{1}{c|}{ Definição } \\
\hline Qualidade & $\begin{array}{l}\text { Ao "fazer as coisas certas", a produção se propõe a influenciar a qualidade } \\
\text { dos bens e serviços da organização. }\end{array}$ \\
\hline Rapidez/Velocidade & $\begin{array}{l}\text { Ao "fazer as coisas mais rapidamente", a produção procura influenciar a } \\
\text { velocidade com que os bens e serviços são fornecidos. }\end{array}$ \\
\hline Confiabilidade & $\begin{array}{l}\text { Ao “fazer as coisas a tempo",a produção objetiva influenciar a confiabilidade } \\
\text { de entrega de bens e serviços. }\end{array}$ \\
\hline Flexibilidade & $\begin{array}{l}\text { A capacidade de "mudar o que e como se faz", em que a produção procura } \\
\text { absorver a flexibilidade, com a qual a empresa produz bens e serviços. }\end{array}$ \\
\hline Custos & $\begin{array}{l}\text { Para empresas que concorrem diretamente em preços, o custo será seu } \\
\text { principal objetivo e provavelmente será o primeiro e principal objetivo a } \\
\text { ser empregado. Quanto menor o custo de seus bens produzidos, ou de seus } \\
\text { serviços prestados, menor poderá ser o preço fornecido aos seus clientes / } \\
\text { consumidores. }\end{array}$ \\
\hline
\end{tabular}

Fonte: Adaptado de Swamidass e Newell (1987), Slack et al. (2007), Paiva (2009)

\subsubsection{Categorias de decisão}

Após as análises e definições dos critérios competitivos, parte-se para a definição das ações que deverão ser implantadas para que os critérios competitivos escolhidos sejam atingidos. Estas ações podem ser divididas em categorias de decisão, que são um conjunto consistente de decisões individuais que impactam na função produção das empresas sob a justificativa de cooperar no alcance dos critérios competitivos desejados (SLACK et al., 2007).

Conforme Slack et al. (2007), as categorias de decisão podem ser divididas por sua natureza em dois grupos: estruturais e infraestruturais. A estratificação das categorias de decisão se faz necessária a fim de contribuir com a organização e sistematização para a facilitação da tomada de decisão. Assim como em relação aos critérios competitivos, nas visões dos autores, pode-se observar que não existe muita diferença entre as categorias de decisão, apenas umas são mais detalhadas que as outras. Para o desenvolvimento deste trabalho, foram utilizadas as estratificações definidas por Slack et al. (2007) para as categorias de decisão.

\subsubsection{Aspectos estruturais}

Para Slack et al. (2007), as categorias de decisão que compõem o grupo de decisões estruturais são classificadas conforme a seguinte disposição no Quadro 2: capacidade de produção, instalações de produção, tecnologia de produção e integração vertical e relação com fornecedores. 


\begin{tabular}{|c|c|}
\hline $\begin{array}{c}\text { Critério Competitivo } \\
\text { Capacidade de } \\
\text { produção }\end{array}$ & $\begin{array}{c}\text { Está relacionada às decisões a respeito da capacidade das instalações, sendo } \\
\text { determinada pela planta, pelos equipamentos e pelos recursos humanos. }\end{array}$ \\
\hline Instalações de produção & $\begin{array}{l}\text { Estão relacionadas às decisões sobre localização geográfica, tipo de processo } \\
\text { produtivo, volume e ciclo de vida. }\end{array}$ \\
\hline Tecnologia & $\begin{array}{l}\text { Envolve desde equipamentos utilizados até processos de produção (por } \\
\text { projeto, job shop, por lote, linha de montagem, fluxo contínuo). }\end{array}$ \\
\hline $\begin{array}{c}\text { Integração vertical } \\
\text { e relação com } \\
\text { fornecedores }\end{array}$ & Está relacionada à decisão de produzir ou comprar. \\
\hline
\end{tabular}

Fonte: adaptado de Slack et al. (2007)

Outros autores exibem diferentes percepções sobre as categorias estruturais. Para Paiva (1995), as instalações de produção estão diretamente ligadas ao nível de foco de cada unidade produtiva e considera, para isto, a localização geográfica, os processos produtivos, o volume de produção e o ciclo de vida dos produtos. Para Pires (1995), deve-se levar em consideração também o mix de produtos, o nível de especificidades dos recursos produtivos, a logística de abastecimento (matéria-prima) e a disponibilidade e custo de mão de obra.

Segundo Hayes (1978) e Wheelwright (1984), as capacidades de produção são decisões ligadas à demanda de mercado, portanto, designando às organizações a decisão de optar por tornar sua capacidade acima, abaixo ou acompanhando a demanda. Como as decisões relacionadas à capacidade produtiva exige das empresas um conhecimento da demanda de produção, no momento em que as mesmas desenvolverem a capacidade de estimar a sua demanda, a capacidade produtiva pode ser dimensionada de forma adequada, não correndo o risco de perder vendas, ou ficando com a sua produção ociosa e elevando o seu custo (SLACK et al., 2007).

A categoria decisiva de tecnologia produtiva é encarada como assunto de técnicos, em que uma decisão, independente da estratégia competitiva organizacional, tem como objetivo único a maximização da eficiência dentro de uma perspectiva gerencial tradicional.Por outro lado, pela perspectiva estratégica, a gerência de operações inclui a percepção quanto aos critérios competitivos elencados sob a concepção da estratégia corporativa, utilizando tal decisão para atingir os objetivos definidos (FLEURY; PROENÇA, 1993). Para Stuckey e White (1993), a integração vertical é uma das decisões mais importantes na estratégia de produção de qualquer organização, definindo seu posicionamento na cadeia produtiva e o grau de relacionamento com os demais elos da mesma (fornecedores e clientes). 


\subsubsection{Aspectos infraestruturais}

As categorias de decisão que compõem o grupo de decisões infraestruturais, segundo Slack et al.(2007), são classificadas conforme a seguinte disposição no Quadro 3: planejamento, controle e organização da produção, força de trabalho e gerência de qualidade.

Quadro 3: Categorias de decisões infraestruturais

\begin{tabular}{|c|c|}
\hline Critério Competitivo & Definição \\
\hline $\begin{array}{l}\text { Planejamento, controle } \\
\text { e organização da } \\
\text { produção }\end{array}$ & $\begin{array}{l}\text { Relacionados diretamente ao suporte das decisões tomadas e à implantação } \\
\text { dos sistemas gerenciais. }\end{array}$ \\
\hline Força de trabalho & $\begin{array}{l}\text { Atua sobre as políticas existentes, para que mantenham os funcionários } \\
\text { motivados, trabalhando em equipe e buscando atingir as metas da empresa. }\end{array}$ \\
\hline Gerência de qualidade & $\begin{array}{l}\text { O gerenciamento desta categoria de decisão deve especificar como as } \\
\text { responsabilidades serão alocadas, que ferramentas de decisão e medição } \\
\text { deverão ser utilizados e quais os métodos de treinamento serão aplicados. }\end{array}$ \\
\hline $\begin{array}{l}\text { Integração vertical } \\
\text { e relação com } \\
\text { fornecedores }\end{array}$ & Está relacionada à decisão de produzir ou comprar. \\
\hline
\end{tabular}

Fonte: adaptado de Slack et al. (2007)

Em relação às categorias infraestruturais, também outros autores exibem percepções divergentes. Para Hayes e Schmeenner (1978), a organização da produção está diretamente ligada às condições organizacionais da empresa a fim de garantir um fluxo eficaz de trabalho, ou seja, são decisões relativas à organização da função produção em função de uma contribuição direta ao cumprimento das estratégias de negócio e corporativa. Em muitas situações, eles são os diferenciais competitivos das organizações. A categoria de decisões denominada gerência da qualidade diz respeito aos controles e garantia da qualidade dos produtos, processos da organização. As decisões inerentes a esta categoria devem definir os padrões e formas de controle da qualidade dos produtos e processos da empresa (NETO, 1999).

\subsection{Processo de formulação de estratégias de produção}

Segundo Platts (1992), após estudar o processo de formulação da estratégia de produção em oito empresas, foi possível perceber que algumas características processuais devem ser perseguidas para se obter um bem-sucedido desenvolvimento de estratégias de produção, as quais serão expostas a seguir. Inicialmente, faz-se necessária uma definição clara da estrutura do processo de formulação, pois os participantes dos processos sentem-se mais seguros e confortáveis ao saberem quais próximos passos serão dados (PLATTS, 1992). Outro fator que deve ser destacado diz respeito à participação individual e em grupo de cada integrante do processo de formulação, com o 
seguintes dimensões sejam do conhecimento do pesquisador a fim de proporcionar um melhor delineamento do estudo: a estratégia de investigação, procedimentos de coleta de dados, procedimentos de registro de dados, o papel do pesquisador, análise e interpretação dos dados.

A estratégia de investigação adotada foi o estudo de caso, que é um estudo de natureza empírica que investiga um determinado fenômeno, geralmente contemporâneo, dentro de um contexto real de vida, quando as fronteiras entre o fenômeno e o contexto em que ele se insere não são claramente definidas. Trata-se de uma análise aprofundada de um ou mais objetos (casos), para que permita o seu amplo e detalhado conhecimento. A principal tendência em todos os tipos de estudo de caso é que estes tentam esclarecer o motivo pelo qual uma decisão ou um conjunto de decisões foram tomadas, como foram implementadas e os resultados alcançados (YIN, 2010). A organização estudada foi uma indústria moveleira fundada a 12 anos, com aproximadamente 90 funcionários e atuação nacional. $\mathrm{O}$ foco de sua produção está centrado na produção de móveis estofados de alto padrão, voltado ao público de Classes A e B.

Como procedimento de coleta de dados, foram utilizadas a entrevista semiestruturada, a observação participante e a análise documental. As entrevistas foram aplicadas a três pessoas da organização - diretor comercial, diretor de $\mathrm{P} \& \mathrm{D}$ e coordenador de compras - seguindo um roteiro de perguntas previamente elaborado. Optou-se por levantar os dados com profissionais provenientes dos níveis estratégico e tático, pois eles estão diretamente relacionados à formulação e à implementação das estratégias de produção. Os dados de observação vieram de forma participante, uma vez que o pesquisador esteve envolvido até recentemente na organização. Observação participante é aquela em que o pesquisador é conhecido e pode registrar informações, caso ocorram (CRESWELL, 2010).

Já os dados provenientes de análise documental vieram de manuais de procedimentos operacionais, catálogos de produção, materiais do departamento de comunicação e atas de reuniões. A análise documental refere-se a documentos, escritos ou não, constituindo o que se denomina fontes primárias. O levantamento de documentos da empresa foi utilizado para permitir aos pesquisadores o acesso de dados complementares às entrevistas.

\section{Os procedimentos de registro de dados foram} utilizados para armazenar os dados coletados. As entrevistas, foram gravadas e posteriormente transcritas.Já os documentos foram fotocopiados para análise posterior. Com relação ao papel do investigador, uma vez que se está utilizando a abordagem qualitativa, que é interpretativa, $o$ investigador está envolvido em uma experiência sustentada e intensiva com os participantes, aumentada pelo fato de alguns dados advirem de observação participante, fortalecendo ainda mais o seu papel. Isso introduz uma série de questões estratégicas, éticas e pessoais ao processo de pesquisa qualitativa (LOCKE et al., 2007 apud CRESWELL, 2010). Com essas preocupações em mente, os investigadores identificam explícita e reflexivamente seus vieses, seus valores e suas origens pessoais, tais como gênero, história, cultura e aspectos socioeconômico, que podem moldar suas interpretações durante um estudo (CRESWELL 2010).

Segundo a perspectiva de Creswell (2010), o processo de análise e interpretação dos dados envolve extrair sentido dos dados do texto e da imagem. Envolve preparar os dados para a análise, conduzir diferentes análises, ir cada vez mais fundo no processo de compreensão 
dos dados, representar os dados e realizar uma interpretação do significado mais amplo das informações. Vários processos genéricos podem ser estabelecidos na proposta para comunicar uma percepção das atividades gerais da análise de dados qualitativos.

\section{APRESENTAÇÃO E ANÁLISE DOS RESULTADOS}

A organização estudada nasceu de um projeto para atender arquitetos e decoradores da alta decoração da grande Florianópolis, estado de Santa Catarina, através de reformas e criações de produtos. Este projeto iniciou-se em junho de 2000, no município de São José, instalado em uma garagem de uma casa de madeira, com apenas um funcionário. $\mathrm{Na}$ época, a empresa, apesar de recém-criada, já possuía know-how, pois seus sócios, mesmo sendo jovens, contavam com experiência no ramo, tendo trabalhado por mais de 15 anos como funcionários de uma grande empresa da alta decoração da Grande Florianópolis, de renome nacional. O negócio começou a fazer sucesso e a demanda pelos produtos aumentou. Então, a partir de fevereiro de 2001, após pesquisa de mercado, os sócios resolveram investir e especializar-se na fabricação de estofados de alto padrão, mudando-se para Santo Amaro da Imperatriz. Todas as unidades estão localizadas em Santo Amaro da Imperatriz, no estado de Santa Catarina. Neste momento, o mercado-alvo passa a não ser apenas a grande Florianópolis, mas sim lojistas do Brasil inteiro.

Atualmente a empresa marca uma etapa de expansão, com a consolidação do mercado nacional e a abertura das exportações. Desde o início, a empresa teve um objetivo definido: desenvolver móveis residenciais autorais, com design $100 \%$ nacional e altíssimo padrão. A empresa produz móveis, principalmente, estofados de alto padrão voltados ao público de Classes
A e B. Seus clientes são principalmente lojistas, estabelecidos em diversos estados do país. A proposta de repensar o mobiliário enquanto objeto de conforto e bem-estar esteve sempre aliada ao acabamento primoroso e à qualidade excepcional, tanto no sistema construtivo como na matéria-prima.

A marca se consolidou no mercado nacional, porém as inovações são constantes e fazem parte dos principais investimentos da empresa. Como no ramo da alta decoração do país existem inúmeros concorrentes que competem das mais variáveis maneiras possíveis, é de suma importância as constantes reformulações e aperfeiçoamentos dos produtos, do atendimento, da forma de venda e pós-venda e principalmente da qualidade destes aspectos. $\mathrm{O}$ processo de venda inicia com a encomenda do consumidor final ao lojista, que repassa o pedido à fábrica. Desta maneira, seu processo produtivo possui as seguintes características: produção sob encomenda,reduzidos estoques de produtos prontos, produção em pequenos lotes ou unitária, não seriados, presença de produtos fora do modelo padrão feitos especialmente para determinado cliente, diversas opções de acabamentos e modelos, renovação periódica dos modelos disponíveis (geralmente anual), oscilação periódica das vendas e consequentemente produção, diversidade de setores produtivos, como serralheria, marcenaria, pintura, estofaria e outros, além da grande variedade de matérias-primas de alta qualidade empregadas. 


\subsection{Formulação das estratégias de produção}

De um ponto de vista abrangente, na empresa, o aspecto estratégia está diretamente ligado ao conceito apresentado por Krajewski (2009), em que a empresa busca técnicas e métodos apropriados para projetar processos que proporcionarão competitividade à organização. Dessa maneira, a empresa direciona sua estratégia corporativa em função de onde quer estar sob as influências dos fatores econômicos, sociais e políticos que possam causar qualquer tipo de turbulência que a afetem diretamente e/ou mesmo que imediatamente, resultando na alteração da estratégia corporativa como um todo.

Sob esta perspectiva, a estratégia corporativa resulta nas ações que definem as estratégias de negócio da organização, em que as expectativas dela são fundamentadas sobre as definições do "onde estar" da estratégia corporativa. Nesta etapa, assim como na anterior, as ações são definidas e aprovadas pelo conselho de gestão da empresa, formado pelos três sócios-proprietários e diretores da empresa, um assessor jurídico e um assessor financeiro-tributário. Conforme entrevista concedida pelo diretor comercial, pode-se perceber a interatividade da organização com o mercado em que está inserida. É através da análise do mercado que a organização acompanha a dinâmica do consumidor e do setor, atuando junto aos clientes e constatando suas necessidades.

Para estabelecer a forma de competição da organização em função de sua disponibilidade de recursos, a organização formaliza sua estratégia de negócio baseada em um orçamento aprovado pelo conselho de gestão, que analisa criteriosamente os investimentos, custos e despesas em função dos resultados projetados. A partir das delimitações de recursos destinados aos planos corporativos da organização, as metas organizacionais são instituídas a fim de assegurar que os objetivos corporativos sejam alcançados. Tais definições geram, por sua vez, as diretrizes para a elaboração da estratégia de produção, que seguem a definição de Corrêa e Gianesi (1994). Os autores definem como principal objetivo da estratégia de produção o aumento da competitividade da organização por meio da padronização coerente de decisões e da organização dos recursos produtivos, para que a otimização destes recursos potencialize a competitividade no mercado de atuação da organização, alinhando as ramificações estratégicas do modelo estratégico proposto pela organização.

NA ELABORAÇÃO DAS

ESTRATÉGIAS DE PRODUÇÃO

ADOTADAS PELA ORGANIZAÇÃO,

A FUNÇÃO PRODUÇÃO

ANALISA COMO EXECUTAR

AS METAS ESTIPULADAS

PARA O INCREMENTO DO

FATURAMENTO ESTIMADO

EM FUNÇÃO DOS RECURSOS

DISPONÍVEIS. ASSIM, O FOCO

DAS AÇÕES SE DIRECIONA

AO GERENCIAMENTO DOS

RECURSOS DISPONÍVEIS, SOB A

PERSPECTIVA DO DESEMPENHO

RECENTE DA FUNÇÃO, DA

CAPACIDADE TECNOLÓGICA, DA

HABILIDADE DO PESSOAL DAS

FUNÇÕES E SUA ORGANIZAÇÃO.

Conforme os estudos de Paiva (2009), como sistemática do processo de implantação da estratégia de produção, a organização deve definir 
os seus critérios competitivos, alinhando-os às suas estratégias de negócio. A partir desta conceituação, a organização realiza o alinhamento de suas estratégias de produção aos critérios competitivos estabelecidos pela estratégia de negócios (critérios que serão abordados mais a diante).

\subsubsection{Estratégias corporativas}

$\mathrm{Na}$ organização estudada, as estratégias corporativas se comportam de acordo com os conceitos exibidos pelos estudos realizados por Slack et al. (2007), nos quais o mesmo afirma que as estratégias corporativas direcionam o restante das estratégias elaboradas pela organização. Conforme Barney e Hesterly (2011), as estratégias corporativas típicas são: a integração vertical, a diversificação, as alianças estratégicas, as fusões e aquisições e a internacionalização. Foi possível observar que a organização realiza o processo de integração vertical para frente, em que ela absorve uma etapa da parte final de sua cadeia de valor. Neste caso, a empresa conta com duas lojas próprias responsáveis por vendas diretamente no varejo. A integração vertical para trás não é algo almejado pela empresa, pois a organização não possui o intuito de absorver os seus fornecedores componentes de sua cadeia de suprimentos. Pelo contrário, existe o desejo de uma redução significativa de produção interna de insumos provenientes do processamento das matérias-primas oriundas de produção externa.

Com relação à estratégia de diversificação corporativa, a organização atualmente não desenvolve nenhum trabalho que se baseia sobre este conceito, pois suas ações são desenvolvidas sob as influências do mercado onde atua, sem a intenção de desenvolver produtos direcionados a outros nichos ou com tecnologias diferentes das utilizadas atualmente. Do ponto de vista corporativo direcionado a alianças estratégicas, fusões, aquisições e internacionalização, a empresa não desenvolve nenhuma atividade que configura tais ações estratégicas. Com exceção da integração vertical, as outras estratégias corporativas não foram analisadas pela organização, que vem adotando este padrão ao longo de sua existência.

\subsubsection{Estratégias de negócio}

Segundo Barneye Hesterly (2011), a estratégia de diferenciação de produto é uma estratégia de negócio em que as empresas buscam ganhar vantagem competitiva, aumentando o valor percebido de seus produtos em relação aos valores de outras empresas. Dessa forma, a empresa adota tal estratégia a fim de fortalecer sua marca sob esta perspectiva de agregar desejo pelos produtos da marca. $\mathrm{O}$ aspecto custo é analisado, comparando sempre os custos aos resultados. Porém, os preços de venda não são definidos por eles, que, quando reduzidos, contribuem apenas para um aumento da margem de lucro da empresa. Assim, a empresa adota a estratégia de diferenciação de produto, não eximindo a participação do custo na formulação estratégica.

A estratégia de negócio da empresa é desenvolvida de forma conjunta entre os diretores da empresa e os três sócios proprietários que atuam de maneira efetiva em cargos estratégicos, formando a alta administração. Dessa forma, os critérios competitivos são gerados a fim de suprir as necessidades da estratégia corporativa. Critérios estes, de acordo com os estudos descritos por Slack et al. (2007), em que são elencados os cinco critérios principais para a posterior estruturação da estratégia de produção de maneira que a mesma possa proporcionar competitividade à organização, sendo 
eles qualidade, velocidade, confiabilidade de entrega, flexibilidade e custos.

Cada critério competitivo é tratado de uma forma diferente pelas organizações em geral. $\mathrm{Na}$ empresa abordada neste estudo não é diferente, porém cada organização elege quais os focos de ação nos critérios que mais resultado pode promover para a organização em seu mercado de atuação. Diante deste fato, analisamos os critérios segundo os aspectos levantados na gestão.

A qualidade na empresa é algo que não é gerenciado de maneira efetiva com a instituição física de um departamento responsável, porém a empresa busca que a mesma esteja presente intrinsecamente em todos os processos realizados, como agente integrante. Prezam por este aspecto, pois alegam ser um fator de diferenciação de seu produto. Assim, quando ocorrem assistências técnicas, ações são tomadas imediatamente para que as situações não se tornem recorrentes, pois a empresa aplica diretamente as ferramentas apontadas nos estudos de Slack et al. (2007), no qual afirma que qualidade é um aspecto importante para a satisfação ou insatisfação do consumidor. Por outro lado, internamente, a produção de qualidade tanto reduz os custos como aumenta a confiabilidade. A confiabilidade de entregas é outro critério competitivo presente na estratégia de negócio. Dessa forma, a empresa entende que este aspecto é indispensável ao seu estereótipo de cliente. Assim, suas referências se adequam às definições de Slack et al. (2007), que afirma ser a confiabilidade um aspecto importante para o consumidor, analisado do ponto de visto externo. Internamente, a confiabilidade dentro da função produção aumenta a confiabilidade operacional, dando mais estabilidade à operação.
O critério velocidade é visto pela organização como algo que gera uma competitividade no mercado, por ser um diferencial entre as empresas do ramo. Ações que permitam reduzir o tempo de ciclo dos processos, sejam eles produtivos ou administrativos, são analisados constantemente, para de otimizá-los e proporcionar resultados diante dos anseios do cliente. Dentre dos aspectos apontados por Slack et al. (2007), a empresa realiza uma aplicação integrada aos conceitos elencados pelo mesmo. A empresa pesquisada apresentou a flexibilidade como critério competitivo, que é definido por Slack et al. (2007) como a capacidade "mudar o que e como se faz". Dessa forma, a produção procura absorver a flexibilidade, com a qual a empresa produz bens e serviços. Assim, a empresa busca manter a flexibilidade a seus clientes como um diferencial de mercado, conservando sempre um planejamento prévio para que a flexibilidade não se torne padrão e para que prioridades sejam estabelecidas cronologicamente, a fim de não prejudicar a função produção como um todo.

O último critério competitivo almejado pela organização pesquisada está associado aos custos, porém a empresa não utiliza o conceito proposto por Slack et al. (2007), em que o autor destaca que quanto menor o custo de seus bens produzidos, ou de seus serviços prestados, menor poderá ser o preço fornecido pela organização aos seus clientes. Para a organização, o que define seu preço de venda não é seu custo, mas o mercado e seus concorrentes. $O$ custo é importante para a organização como forma de projetar sua rentabilidade. Dessa forma, como consequência da necessidade da estratégia de negócios, os custos são gerenciados em seus mais amplos níveis, conforme foi mencionado anteriormente. O Quadro 4 exibe a forma com que a empresa aplica os critérios competitivos em função da conceituação de Slack et al.(2007). 


\begin{tabular}{|c|l|l|}
\hline Critérios & \multicolumn{1}{|c|}{ Para a organização... } & \multicolumn{1}{c|}{ Na prática... } \\
\hline Qualidade & Produtos e processos. & A qualidade está intrínseca nos processos. \\
\hline $\begin{array}{c}\text { Confiabilidade } \\
\text { de entregas }\end{array}$ & Credibilidade do cliente. & $\begin{array}{l}\text { A empresa valoriza a credibilidade gerada } \\
\text { pelo cumprimento de suas definições } \\
\text { junto aos seus clientes. }\end{array}$ \\
\hline Velocidade & $\begin{array}{l}\text { Tempo de ciclo curto, um diferencial } \\
\text { de mercado. }\end{array}$ & $\begin{array}{l}\text { Aorganização está em constante pesquisa, } \\
\text { análise e estudo para a redução de seus } \\
\text { tempos de ciclo dos processos. }\end{array}$ \\
\hline Flexibilidade & $\begin{array}{l}\text { Adaptação da produção de alteração } \\
\text { no planejamento em função das } \\
\text { necessidades de urgência dos clientes. }\end{array}$ & $\begin{array}{l}\text { Prioridades são redefinidas, sempre } \\
\text { buscando atender às necessidades do } \\
\text { cliente,sem prejudicar a função produção. }\end{array}$ \\
\hline Custos & $\begin{array}{l}\text { Maior rentabilidade. } \\
\text { Ocusto éavaliado pela empresa em todos }\end{array}$ \\
\hline
\end{tabular}

Fonte: Adaptado de Slack et al. (2007)

Dessa forma, os diferenciais apontados como responsáveis pela competitividade dos produtos produzidos pela empresa são impulsionados pelos critérios competitivos adotados pela organização, mantendo uma conexão entre os objetivos corporativos ao posicionamento de mercado adotado.

\subsubsection{Estratégias de produção}

As estratégias de produção na empresa estudada são fundamentadas e aplicadas seguindo os critérios de Platts (1992), em que afirma que a estratégia de produção é definida como um padrão de decisões que envolve duas linhas paralelas de aspectos, as estruturais e as infraestruturais. Esses aspectos determinam como o sistema produtivo deverá operar o conjunto de objetivos produtivos e sua contribuição para o alcance dos objetivos competitivos da organização. Assim, a organização alinha suas estratégias de produção em função das necessidades das estratégias de negócio e corporativas definidas e aprovadas pelo conselho de gestão. Dessa maneira, as estratégias de produção na organização geram as categorias de decisões em função das ações que deverão ser implantadas para que os critérios competitivos definidos sejam atingidos. Tais categorias de decisão foram estratificadas neste trabalho segundo os critérios de Slack et al. (2007), em que elas são divididas em categorias de decisões estruturais e infraestruturais.

\subsubsection{Análise estratégica estrutural}

Para Slack et al.(2007), as categorias de decisão que compõem o grupo de decisões estruturais são classificadas conforme a seguinte disposição: capacidade de produção, instalações de produção, tecnologia de produção e integração vertical e relação com fornecedores. Com 
relação à capacidade de produção, a empresa não possui um plano de vendas que possa projetar antecipadamente as necessidades de produção. Assim, o departamento de vendas se adequa à sazonalidade do mercado. Dessa forma, não é possível determinar um plano de produção baseado numa previsão de venda, gerando ações em consequências das geradas pelo mercado, ou seja, a produção se projeta de acordo com as necessidades da área de vendas. A política estratégica da empresa preza pela alocação externa da capacidade produtiva. Assim, caso existe a necessidade de aumentar a capacidade produtiva, a função produção opta por maximizar o seu potencial produtivo com terceirizações e parcerias.

Do ponto de vista de instalações, o objetivo da empresa é manter suas áreas produtivas no mesmo parque fabril, eliminando riscos de avaria no transporte interno de mercadorias de uma área produtiva para outra, gastos com logística, mudanças e desperdício de tempo de colaboradores envolvidos no processo de carga e descarga, entre outros aspectos, constituem as principais justificativas deste processo. $\mathrm{O}$ volume de produção é facilmente absorvido pela estrutura produtiva em virtude da alta velocidade com que mercadorias são expedidas. Assim, a quantidade produtos acabados formam um pequeno estoque, que é renovado em uma média a cada cinco dias. $O$ processo produtivo se encontra disposto de uma forma que não contribui de uma maneira dinâmica para o abastecimento da linha produtiva, em função do almoxarifado central encontrar-se longe da maior parte da área produtiva, prejudicando também o processo de descarga de materiais. Por outro lado, a linearidade da disposição do processo contribui para a expedição das mercadorias, seguindo um fluxo produtivo eficiente, sem muitas ramificações e remanejamentos dos produtos dentro da linha produtiva.
A organização utiliza processos tecnológicos e seus recursos dentro das disponibilidades de seu ramo de atuação. Atualmente, conta com um sistema ERP de ponta, desenvolvido de acordo com as necessidades da empresa em seus mais amplos aspectos. Em alguns de seus processos produtivos, que, em sua grande maioria, são manuais e artesanais, a empresa investe em automatização. Comparando as aquisições da empresa à disponibilidade tecnológica do ramo, pode-se avaliar apenas o CNC como não aproveitado dentro do processo, por falta de padronização de alguns processos e por existir centros de usinagens mais modernos que executam um maior número de cortes, deixando o produto pronto, além de eliminar alguns processos pós-corte realizado atualmente.

\section{Quanto à integração vertical e à relação com}

os fornecedores, observou-se que a organização não possui o intuito de absorver os seus fornecedores componentes de sua cadeia de suprimentos. Pelo contrário, existe o desejo de uma redução significativa de produção interna de insumos provenientes do processamento das matérias-primas oriundas de produção externa, pois o foco da empresa é desenvolver produtos acabados e não matéria-prima, uma vez que a absorção dos processos de produção e processamento das matérias-primas utilizadas pela organização possuem um alto custo de implantação. Sobre os fornecedores, atualmente a empresa conta com um procedimento padrão para seleção de fornecedores, descrito em sua política de compras, que conta com pré-requisitos básicos, como preço, prazo de pagamento, qualidade, prazo de entrega para a inserção dos mesmos em sua cadeia de suprimentos. $\mathrm{O}$ intuito principal da relação com os fornecedores está na construção de uma sólida parceria, não estruturada apenas sob preços de produtos e condições de pagamento e fornecimento, mas sim sob a relação próxima entre empresa e 
fornecedor. A organização não conta com um gerenciamento de indicadores de desempenho de seus fornecedores.

\subsubsection{Análise estratégica infraestrutural}

As categorias de decisão que compõem o grupo de decisões infraestruturais segundo são classificadas conforme a seguinte disposição: planejamento, controle e organização da produção, força de trabalho e gerência de qualidade. Em relação ao planejamento, controle e organização da produção, verificou-se que a função produção encontra-se organizada hierarquicamente sob uma visão e gestão moderna, sem os diversos subníveis de direção, gerência, coordenação e supervisão que se pode observar comumente nas empresas. Assim, a organização possui uma diretoria industrial que direciona diretamente os supervisores de produção, que são quatro no total, e que, por sua vez, repassam as ações aos colaboradores. Atualmente o processo de produção é dividido em três áreas: estofaria, marcenaria, metalurgia, que por sua vez são divididas em setores. Verificou-se que cada setor produtivo possui seus deveres e obrigações bem definidas a partir do plano de produção coordenado pela diretoria industrial. O departamento de Planejamento e Controle de Produção utiliza o sistema ERP da empresa para determinar o planejamento da produção. As capacidades produtivas são mensuradas por homem/hora e os sequenciamentos levam em consideração a disponibilidade de capacidade,o prazo de entrega, a disponibilidade de tecido e o melhor mix de produtos a serem produzidos, utilizando o máximo de capacidade de todos os setores produtivos. Hoje a empresa baseia seus estoques diante da política de estoque zero. Suas estocagens são baseadas em uma programação de compras que parte do processamento das informações de necessidade do pedido no momento da triagem do mesmo pelo departamento comercial, dentro de um modelo de MRP. Os prazos de ressuprimentos por parte de seus fornecedores são considerados para que o nível de estoque se mantenha o menor possível dentro do prazo de reabastecimento, evitando possíveis faltas de insumos no departamento produtivo.

Sob a ótica da força de trabalho, a empresa possui um modelo de gestão compartilhada, em que os membros das diretorias participam ativamente da disseminação de metas e resultados, contribuindo de forma muito positiva na estrutura organizacional. A organização considera que é de extrema importância os treinamentos dos funcionários da produção, que devem ser capacitados de acordo com a necessidade de seu setor produtivo. Este treinamento pode ser moldado também para a aquisição de polivalência do funcionário. Atualmente o plano de treinamento é bem superficial.

Com relação à gerência da qualidade, a gerência de produção possui ferramentas no sistema de informação também para gerenciar os tempos produtivos de seus colaboradores, em que um relatório informa onde os tempos de cada colaborador foram gastos, contabilizando suas horas produtivas e improdutivas. Os processos de melhorias nos aspectos produtivos são influenciados e direcionados por todos os departamentos da organização que, de forma conjunta, buscam auxiliar em um melhor desempenho da operação como um todo. Porém, atualmente tais informações não são utilizadas para o fim referido e as melhorias de processos são realizadas conforme a identificação de necessidades, problemas com o produto ou reclamações e/ou sugestões de clientes. 


\subsection{Implantação das estratégias de produção}

O processo de formulação das estratégias da organização não é formalmente estruturado. Dessa maneira, o conselho de gestão realiza e estabelece os caminhos que a empresa deverá tomar em função das análises do mercado e prospecções da organização e, em conjunto, define as metas e ações que a empresa deverá tomar para que tais objetivos sejam alcançados. O próprio conselho define o foco no critério competitivo a ser adotado por determinada área como prioridade em função da estratégia de negócio. São utilizadas ferramentas e análises semelhantes às metodologias Hill e Platts-Gregory para a geração de seus critérios competitivos. Posteriormente à definição de cada critério e das diretorias envolvidas nas implementações, as estratégias são repassadas para a definição das ações que deverão ser instituídas a fim de gerar os resultados almejados pela organização.Assim, definidas as estratégias, as ações são colocadas em prática e os resultados mensurados sob a forma de relatórios ou através de reuniões, para finalmente serem repassados à gestão com o intuito de se analisar o alinhamento da estratégia aplicada.

A metodologia Hill dá grande ênfase à integração entre marketing e produção. Em virtude disso, desenvolveu-se critérios qualificadores e ganhadores de pedidos, estreitando ainda mais a relação entre os diferentes mercados de atuação e da valorização dos critérios competitivos idealizados na estratégia de negócios por parte da organização. Segundo Slack et al. (2007), o modelo sugere a conexão entre os diferentes níveis da estratégia, que é dividida em cinco passos, sendo eles: definição dos objetivos da organização, estratégia de marketing, como os produtos ou serviços ganham pedidos, quais as estratégias de ocupação do processo e da infraestrutura. Com relação aos objetivos da organização, essa tem como objetivo comum realizar um crescimento anual estimado de 5\% ao ano, tendo uma lucratividade média de $20 \%$ do total faturado mensal. O fluxo de caixa é atualmente um fator determinante para todas as ações da empresa no âmbito geral, pois o mesmo direciona as necessidades de atuação da gestão. Este fluxo é controlado semanalmente, avaliando o desempenho atual das entradas geradas pela expedição de mercadorias e a necessidade futura de faturamento dos 15 dias subsequentes, analisando as despesas gerais e a receita que deverá ser gerada a partir das informações do departamento de planejamento de produção. Em relação à estratégia de marketing, um dos diferenciais da empresa é sua extensa gama de produtos, sendo um diferencial de mercado a sua marca ser completa em decoração. Outro fator propulsor de vendas é a inovação da coleção que ocorre todos os anos no mês de outubro, sendo que esta renovação segue as tendências dos principais polos de designers do mundo.

\section{Com relação a como os produtos ou serviços}

ganham os pedidos, os maiores diferenciais para o bom desempenho da marca estão atrelados à garantia da qualidade, trabalhando no programa de qualidade assegurada ao cliente, a confiabilidade e credibilidade que a marca tem com seus parceiros, muitos desde o surgimento da empresa. Os prazos de entrega são outro ponto positivo no processo de produção, pois a empresa presa por assegurar a entrega de seus produtos na data prometida a seus clientes. Muitas vezes, assume contratos em que um atraso de entrega gerar multa à organização, sendo que este fator gera muita credibilidade para a marca.

As estratégias de ocupação são denominadas por Slack et al. (2007) como escolha do processo, com o intuito de definir o conjunto 
de características estruturais da operação que são consistentes entre si e apropriadas à forma como a organização deseja competir. Em alguns de seus processos produtivos, que em sua grande maioria são manuais e artesanais, a empresa investe em automatização. No setor de marcenaria, conta com um CNC moderno. Já o setor de metalurgia conta com modernos equipamentos de lixa e polimento de aço inox, e o setor de risco e corte de tecidos conta com a mais nova aquisição da empresa, um CNC de corte de tecido a laser. A capacidade da empresa atualmente encontra-se definida através de cronoanálise dos processos produtivos. Desta forma, o departamento de vendas realiza suas vendas de acordo com a ocupação das capacidades fabris de maneira a não extrapolar os limites produtivos e não prejudicar os prazos de entregas dos produtos aos clientes. $\mathrm{O}$ sistema de Planejamento e Controle de Produção (PCP) dá suporte e determina a infraestrutura necessária para o desempenho adequado da organização. $\mathrm{O}$ mesmo determina as ações a serem desempenhadas pelos departamentos de compras, comercial, almoxarifado, recursos humanos, manutenção, expedição, financeiro, tudo a partir do planejamento de produção. Após executado o planejamento, o departamento processa as informações referentes ao consumo de matérias-primas necessárias para a produção e verifica as necessidades de compra e, em caso de necessidade, aciona o departamento de compras. Da mesma forma, restringe ou aciona o departamento comercial no caso de baixa de pedidos em carteira. O PCP também libera as listas geradas pelo ERP da empresa para o almoxarifado distribuir os insumos necessários para a produção do planejamento no período desejado e verifica a necessidade de recursos humanos necessários para a execução do planejamento. Em caso de necessidade, aciona o RH. O fluxo financeiro da empresa é baseado no planejamento de produção, que determina a entrada de capital na organização por meio da expedição de mercadorias.

Outro método utilizado para dar sustentação e direcionamento das ações a serem desenvolvidas na estratégia de produção são direcionadas pelo método Platts-Gregory, que, conforme Slack et al. (2007), consiste em desenvolver a compreensão da posição de mercado da empresa e da identificação dos fatores exigidos pelo mercado, comparando esses elementos ao nível de desempenho atingido em função da operação. Assim, é possível analisar os aspectos definidos pela organização como importantes ao desempenho atual de seus concorrentes: prazo de entrega, confiabilidade,características, qualidade, flexibilidade, volume, preço/custo. Dessa forma,é possível observar quais os fatores que são relevantes no mercado de atuação e os que, em relação aos concorrentes, precisam ser melhorados em virtude do desempenho da função produção, contribuindo diretamente para o alinhamento da estratégia de produção.

\section{CONSIDERAÇÕES FINAIS}

O estudo aqui descrito teve como objetivo investigar como são formuladas e implementadas as estratégias de produção em uma empresa do setor moveleiro. Utilizou-se a abordagem de pesquisa qualitativa e a estratégia de estudo de caso. Os principais resultados alcançados com o estudo podem ser sumarizados nos seguintes pontos: 
a) a função produção, na prática, possui valorização da organização como diferencial competitivo;

b) a organização não possui um processo de formulação de suas estratégias formalmente definido;

c) a organização não possui ferramentas formalizadas para a geração de suas estratégias;

d) as ferramentas e técnicas, mesmo que sejam adaptações a metodologias consagradas, geram resultados eficientes para a organização;

e) os critérios competitivos são bem definidos pela estratégia de negócios, porém o aspecto qualidade não é gerenciado conforme a definição da estratégia;

f) os impactos das estratégias sob a função produção não são mensurados de maneira eficiente;

g) as categorias de decisão são tratadas e recebem os devidos planos de ações, porém não existe formalidade na categorização das decisões por parte da estratégia de produção;

h) a estratégia de produção não atinge os níveis operacionais de maneira eficiente.

Dentro dos aspectos levantados como passíveis de melhorias está a formalização do processo de formulação das estratégias da organização.
As ferramentas e técnicas, mesmo que sejam similares a metodologias consagradas, geram resultados eficientes para a organização, porém podem ser migradas às metodologias como a de Hille a de Platts-Gregory.A comunicação entre as partes envolvidas no processo de formulação e implementação das estratégias de produção também pode ser otimizada pelo uso de rotinas formalizadas para tal. Isso evitaria possíveis falhas no direcionamento de algumas ações. É importante que a organização evite separar os processos de formulação e de implementação das estratégias, tendo em vista aproveitar contribuições dos diversos envolvidos, direta e indiretamente, no processo. A organização deve incorporar o aprendizado contínuo, uma vez que, assim, ela pode aproveitar estratégias emergentes, fruto desse aprendizado.

Os critérios competitivos são bem definidos pela estratégia de negócios, porém o aspecto qualidade não é gerenciado conforme a definição da estratégia. Nesse sentido, não há um controle efetivo da qualidade durante os processos, existindo apenas uma expectativa por parte da organização da existência intrínseca da qualidade. As categorias de decisão são tratadas e recebem os devidos planos de ações, porém não existe formalidade na categorização das decisões por parte da estratégia de produção. Dessa forma, é importante criar certo nível de formalismos nas ações, mas não deixando que o excesso de formalidades atrapalhe o pensamento criativo e a identificação de oportunidades de melhoria. 


\section{FORMULATION AND}

IMPLEMENTATION

OF PRODUCTION

STRATEGIES: A

CASE STUDY IN

A FURNITURE BUSINESS

\section{REFERÊNCIAS}

BARNEY, J. B.; HESTERLY, W. S. Administração estratégica e vantagem competitiva. 3. ed. São Paulo: Pearson Pretice Hall, 2011.

CARIDADE, M. D.; TORKOMIAN, A. L. V. Estratégias de produção das empresas cerâmicas de Santa Gertrudes. Cerâmica Industrial, v. 6, n. 1, p. 32-39, 2001.

CORREAA, H.; GIANESI, I. Administração estratégia de serviços. Fundação Vanzolini, São Paulo: Atlas, 1994.

CRESWELL, J. W. Projeto de pesquisa: métodos qualitativos, quantitativos e misto. 5. ed. Porto Alegre: Artmed, 2010.

D'ANDRÉA, C. Estratégias de produção e organização de informações na web: conceitos para a análise de documentos na internet. Ciência da Informação, v. 35, n. 3, p. 39-44, 2006.

FLEURY, P. F.; PROENÇA, A. Competitividade industrial e a gerência estratégica de operações. Revista de Administração, v. 28, n. 2, p. 3-21, 1993.

HARRISON, J. S. Administração estratégica de recursos e relacionamentos. Porto Alegre: Bookman, 2005.

HAYES, R.; SCHMEENNER, R. W. How should you organize manufacturing? Harvard Business Review, 1978.

KRAJEWSKI, L.J. Administração de produção e operações. São Paulo: Pearson Pretice Hall, 2009.

MATTOS, L. K. As mudanças organizacionais e seus gestores nas empresas na era da informação. 2002. Dissertação (Mestrado Executivo). Fundação Getúlio Vargas, São Paulo, 2002.

MINTZBERG. H.; AHLSTRAND, B.; LAMPEL, J. Safari de estratégia: um roteiro pela selva do planejamento. São Paulo: Bookman, 2000.

MUSCAT, A.; FLEURY, A. Indicadores de qualidade e produtividade na indústria brasileira. Revista Indicadores de qualidade e da produtividade, v. 1, n. 1, p. 57-78, 1993.

NETO, J. P. B. Formulação de estratégias de produção industrial. Porto Alegre, 1999. 


\section{SOBRE OS AUTORES}

PAIVA, E. L. Conhecimento organizacional e o processo de formulação de estratégias de produção. 1999. Tese (Doutorado). Universidade Federal do Rio Grande do Sul, Porto Alegre, 1999.

PAIVA, E. L. Estratégia de produção e de operações: conceitos, melhores práticas, visão de futuro. 2. ed. Porto Alegre: Bookman, 2009.

PIRES, S. Gestão estratégica da produção. Piracicaba, SP: Ed. Unimpe, 1995.

PLATTS, K. W.; GREGORY, M. J. A

Manufacturing audit approach to strategy

formulation In: Manufacturing strategy: process and contents. Chapman and Hall, 1992.

PORTER, M. Estratégia competitiva: técnicas para análise de indústria e da concorrência. 7. ed. Rio de Janeiro: Campus, 1986.

SALLES, J. Gestão estratégica da manufatura. Tese (Doutorado em administração) São Paulo, 1998, 145 f - Escola de Administração da Fundação Getúlio Vargas. São Paulo, 1998.

SANTOS, F. C. A.; PIRES, S. R. I. Prioridades competitivas da administração estratégica da manufatura: estudos de casos. In: Encontro Nacional de Pós-Graduação em Administração, 22, Foz do Iguaçu/PR, 1998.

SKINNER, W. Manufacturing: missing link in corporate strategy. Harvard Business Review, 1969.

SLACK, N.; CHAMBERS, S.; JOHNSTON, R. Administração da produção. São Paulo: Atlas, 2007.

STUCKEY, J.; WHITE, D. When and when not to integrate. Sloan Management Review, Spring, 1993.

SWAMIDASS, P. M.; NEWELL, W. Manufacturing strategy, environmental uncertainty and performance: a path analytic model. Management Science, v. 33, n. 4, p. 509-524, 1987.

WEELWRIGHT, S.; HAYES, R. Restoring our competitive edge: competing through manufacturing. Toronto: Wiley, 1984.

YIN, R. K. Estudo de caso: planejamento e método. 4. ed.. São Paulo: Bookman, 2010.

Data de recebimento: 31/10/2013

Data de aprovação: 13/12/2016

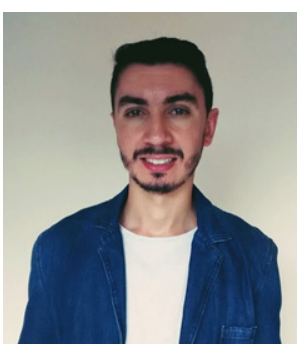

Diego Madalena

Graduado em Gestão de Produção Industrial(SENAI -SC) e especialista em Gestão Estratégica Empresarial (SENAC - SC). Experiência na área industrial desenvolvendo trabalhos de estruturação, operacionalização, implementações e implantações nas áreas de Planejamento e Controle de Produção, Estoques, Compras, Engenharia de produtos, Sistema de Informação (implantações, automatização de processos e gerenciamento de cronogramas de implantação), Mapeamento de Processos, Custos Industriais (estruturação de custos, definição de preço de venda, controladoria industrial) e Pesquisa e Desenvolvimento de novos produtos e processos. Atualmente é Sócio e Gestor de Projetos na empresa Megadev Tecnologia.

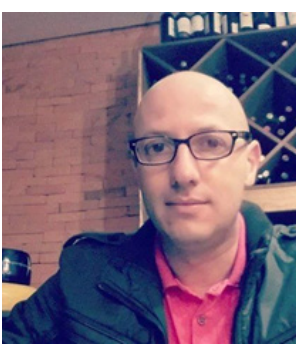

PierryTeza

Graduado em Administração de Empresas pela Faculdade Estácio de Sá de Santa Catarina (FESSC). Especialista em Engenharia de Produção pelo Centro Universitário Leonardo da Vinci (UNIASSELVI). Mestre em Engenharia de Produção e doutorando em Gestão do Conhecimento pelaUniversidade Federal de Santa Catarina(UFSC). Professor do Instituto Federal de Santa Catarina (IFSC). Experiência docente em disciplinas da área de empreendedorismo, marketing, estratégia e métodos científicos. Experiência profissional na área de consultoria técnica e gerenciamento de projetos e obras de engenharia.Membro do Grupo de Pesquisa Inteligência, Gestão e Tecnologias para Inovação (IGTI/UFSC) e do Grupo de Estudos e Pesquisas em Empreendedorismo e Inovação(GEPEI/IFSC). Desenvolve pesquisas em Gestão da Inovação com 
foco em Métodos, Técnicas e Ferramentas para

Inovação (MTF-Is).

**** 